\title{
Attack training in Basketball game---False action's teaching and training mode
}

\author{
Wei-Xiang HE \\ Fuzhou University Sports Teaching Research Department \\ Fuzhou City Fujian Province
}

\begin{abstract}
Basketball game is a strongly competitive sport with two sides always in the state of attack or defense. As one of the attack techniques, false attack, if trained properly and enough, will do good to athlete, including to help them get to know how false action works and help them develop their thinking ability and keen observation when they are playing, thus help them see more and catch more chance to attack. This paper mainly studies the theory and function of false action in basketball game, introducing several types of false action, their characteristics and rules, finally offer some strategies for false action's teaching.
\end{abstract}

Keywords: basketball's attack training; false attack; training mode in teaching

Basketball game is a really competitive sport, requiring a high qualified technique, fast speed and enough strength. As a basic technique in basketball game, false action plays a key role in no matter daily training or real competition. Put attention on analyzing the rules and characteristics of false action and put into enough practice, basketball athlete's technique level will be improved without doubt, thus our basketball game will boom step by step.

\section{ANALYSIS TO THE THEORY AND FUNCTION OF FALSE ACTION}

False action is usually a method and technique for basketball athlete to disturb rival and then open up the opposition defense. It needs one to be flexible on body change and cooperation with his teammates. False action can be carried out through following types: step-moving, basketball player rotates in the place or quickly move to different directions; body posture, player attacks with false action through body shake to different directions; cooperation with teammates, in daily training or real competition, player can do false action by himself or with some teammates; two systems of false action, player can use false action to attack with basketball in his hand or just himself. In basketball game, the reason a player use false action is to make the rival get the wrong information, then he can break through the rival's defense and thus get the chance to pass or shoot [1].

False action used to make rival be puzzled on what one will do next. It's a common strategy. Anyone who uses it can help himself take an active part, having more chance to score. An excellent basketball player can make his false action as real as possible so that opponent can't tell, and at this moment, he can also provide opportunity for his teammate's attack and pass. Though we know that false action is fake, one will not really have this action as people see, but all the mind and technique that reflected in it are all real and rather valuable for each move one takes is after a careful consideration on time and chance. It's really technical so that people hard to distinguish. Only when one

\section{II.THE TYPES, CHARACTERISTICS AND RULES OF FALSE ACTION}

\section{A. The Types}

In order to cover up actual intention, basketball player will use false action, which can be clarified into three types below:

The first one called "look one way and row another". Player knows what the opponent's next move, then he will make some moves deliberately to attract the opponent's attention, and when it successes, then he will have his real move. For instance, one forecasts that someone will have blocked shots on him when he rushes to the basket and shot, then he will make others think that he wants to shot, and at this moment he passes the ball to his teammate when the opponent tries to jump to defense.

The second one is "advantage the enemy's plot". When one attacks, he uses his general action, and then observes what the opponent reflects, if the opponent doesn't respond to it, then he makes it into real action, but if not, he will make it into a fake one to disturb him then have another move. For example, one means to pass the ball overhead, if the defense one didn't make any response, he will pass it as he intends to, but if the defense one jump up to have blocked shot, then he will change the pass action to break through with ball in hands.

The last one is "play by ear". Player takes correspondent actions to reply things in emergency. Layup is one example of it.

\section{B. The Characteristics and Basic Rules}

The key to false action is one word--- "change". Attack with false action doesn't have a set of fixed move mode, like the saying goes "water is not always flowing as it was, army doesn't fight in the same formation". Usually, the place of attack is closely related to the rule of false action. The farer the distance to the basket area is, the more abundant of the false action can be. For example, when one stands quite far from the basket area, then he has much more room to move forward or back, move from left to right or have actions like jump, in these kinds of way close to the basket area gradually.

1) The manifestation of attack place and false action

In the place of small forward, false action like move from left to right, forward to back and twist. Ginobili from NBA Spurs is the represent; in the place of power forward, false actions are mainly moves from left to right, up to down and 
twist, Scola from the rockets is one of them; in the center position, the manifestation are left to right and twist, represented by Howard from Orlando; in the back and control position, false action has to be more comprehensive with all the techniques that have been covered ahead, and this is represented by Rose from the Bulls.

2) Basketball player in different shapes has different false action though in the same position

If it's in the forward position, according to different shapes, the manifestation can be: strong and tall player have more chance to make false action than short one, typical example is James to Ginobili. And usually the comparatively strong one have more twists as his false action, represented by Yaoming.

After all these analysis to the rules, players can form a set of false action based on their own strong point. Plus effective techniques, one can make his attack more direct and forceful, therefore, can help him break through all the defense and make success.

\section{TRAINING MODE IN TEACHING OF FALSE ACTION IN BASKETBALL'S ATTACK TRAINING}

\section{A. Training Techniques of False Action}

\section{1) Basic Techniques}

Grasp basic posture launch is the premise of training to false action. Basic training is fundamental, like jumping, quick and short steps in place, quick launch practice in place and listen to directions from different ways at the same time and then move quickly [2].

Have more all kinds of running posture to improve player's flexibility and coordination. Running back and forth are two common ways.

Turn-around technique also needs much practice, which helps players to be more prompt. For example, turn-around from forward side to back side, half turn-around and whole one.

\section{2) Technique of false action with bare handed}

Set up practice like cross barriers by false action with bare handed. In the process, player must keep body flexible and coordinate, and make his action bigger and bigger.

Practice in pair with one attack and one defense. Player's ability of attack and defense will be improved a lot. Practice of one attack and one defense with bare handed will do good to their ability of both.

Have holding ball practice under the condition of no defense. Shake the ball to different directions in one position, and the same, have bigger and bigger move when they are holding the ball. Action is lifelike enough to jump shot.

\section{3) Training of passing with false action}

As a basic technique action in basketball game, passing with false action has several points to watch out: bounce pass and passing with single hand or both hands are the primary passing techniques, which need to be practiced enough before one is able to make bounce pass; then the power, the speed and the precision when one passes ball also have to be practiced many times; after all the practices done, then one can have practice on passing with false action, and during this process, player still needs to learn to observe the opponent's purposes then break it.

Training of break though with false action

When player trains to break through with false action, he needs to be told break through with firm steps, and the choosing of false action depends on where the opponent stands on; the training of false action can combine break through and shoot together, making one can cut actions flexibly. When one wants to use false action when he is breaking through, break through is not the only intention, he needs to observe firstly and then see chances to pass ball or even shoot.

Training of shoot with false action

Shoot in basketball game is one of the most important attack techniques. The training of shoot needs to be combined with passing and all of real or fake shoots. Player makes some shoot actions through a series of shake action like head shaking and arm shaking, making the opponent can't really tell what you want to do, and then very quickly, jump and shoot, making the false shoot become a real one. One shoots, then one got the chance to score, so it's very essential in the whole basketball game, which also directly related to the result and whether this game brilliant or not.

\section{B. Teaching and Training of Attack False Action}

From one's attack false action, we can tell how his technique and basketball awareness are. It needs player have a flexible and coordinate body. As for training in this aspect, false action with whole body, steps and passing need to be practiced more.

a) False action with whole body

Player needs to hold the ball with body leaning to forward, foots separate to below one's shoulder or even more. Keep eyes look forward, holding the ball and shake body according the move and speed of the ball. One can choose a proper tempo for passing, like 1-2 slow, 3-4 quick, 1-2 quick and 34 slow.

b) False action with steps

Player moves with certain tempo and certain step movement, matching the body with the passing false action to puzzle the opponent.

c) False action when passing

Player has all kinds of training for passing, like passing chest pass, hook pass and bounce pass. Player needs to strengthen his ability to control the ball so that he can flexibly transfer his movements when it's need.

\section{d) False action in succession}

Under different condition, player needs different false action. For making the opponent fail to tell what your real intention is, you need to take a series of false action so that can break through one after one. For example, use false action like move from right to left when one got defense on him, then at some moment go the opposite direction and do it very quickly [3]. And in order to make sure that one's false action as real as possible, he needs to keep his step firmly, and make false action. At this moment, body moves to the opposite direction of the ball moves to, making others think as he wants to break through with ball in hands. But actually he knew it 
and takes it back and then do the same but in the other direction. One can clearly know the opponent's response after repeating this twist movement twice. He will know there is 0.1 second for people to have response, so he can make full use of it to cut into key area or passing ball [4].

\section{CONCLUSION}

As everybody knows, basketball is a strongly competitive sport which requires player possessing certain awareness, the same to people love basketball. False action, as a common action be used in real basketball game, playing a great role on player's attack, break through and shoot. False action is not fixed in certain movements or rules for there are so many uncertain on real competition, therefore, player needs to have enough practice on it and then can use it flexible depending on his own need. Player use false action to make the opponent fail to tell what one really wants to do next so he can have time to take the active and then score. All of these require a flexible and coordinate body, and needs good basketball awareness and ability to observe, thus, anyone loves basketball and wants do good on it must practice as much as he can.

\section{REFERENCE}

[1] The characteristics, rules and training ways of false action in basketball attack technique[J]. Yang Husheng. Hubei Sports Technology, 2012(2):56-57

[2] How to improve the application of false action in basketball game[J]. Ma Dong. Journal of Taiyuan City Polytechnic Institute, 2013(3): 8990

[3] The application of false action in attack and defense[J]. Lv Qichuan. Technology View, 2013(25): 102-103

[4] False action of defense in basketball competition[J]. Rong Jinwen. Journal of Nanjing Sports Institute, 2006(4):60-61 